\title{
Clinical Practice of Gastrointestinal Endoscopy in COVID-19 Patients: An Experience from Indonesia
}

\author{
Rabbinu Rangga Pribadi ${ }^{1,2}$, Amanda Pitarini Utari ${ }^{1,2}$, Virly Nanda Muzellina ${ }^{1,2}$, Saskia Aziza Nursyirwan ${ }^{1,2}$, Hasan Maulahela, \\ Kaka Renaldi ${ }^{1,2}$, and Ari Fahrial Syam ${ }^{1,2}$ \\ ${ }^{1}$ Division of Gastroenterology, Pancreatobiliary and Digestive Endoscopy, Department of Internal Medicine, Cipto Mangunkusumo \\ National Central General Hospital, Faculty of Medicine Universitas Indonesia, Jakarta, Indonesia, ${ }^{2}$ Indonesian Society for Digestive \\ Endoscopy
}

The burden of the coronavirus disease 2019 (COVID-19) has been rapidly escalating across countries globally, and Indonesia is no exception. ${ }^{1}$ As of February 18, 2021, the total number of cases in Indonesia had reached 1,252,685, with a $2.7 \%$ case fatality rate. ${ }^{2}$ It has significantly affected the healthcare system, with nearly all hospitals in Indonesia taking on a large number of COVID-19 cases. Our workplace, Cipto Mangunkusumo National Central General Hospital, is a national referral hospital and is currently capable of providing comprehensive diagnostic and therapeutic methods for COVID-19 patients.

Numerous COVID-19 patients have been admitted to our hospital with various diseases or comorbidities. The presenting symptoms and signs range from respiratory to gastrointestinal manifestations. Many of these patients required gastrointestinal (GI) endoscopy, which could be urgent, semi-urgent, or elective. However, the pandemic has considerably changed the mindset and practice of endoscopists. A study by Zein et al. ${ }^{3}$ showed that $56.5 \%$ of Indonesian GI endoscopists had discontinued their endoscopy practice. Han et al. ${ }^{4}$ described that in
South Korea, they still performed GI endoscopies with strict indications, albeit in limited numbers. The main concerns were not only patient safety, but also medical personnel safety, which has resulted in adaptation of the digestive endoscopy practice during the COVID-19 pandemic. ${ }^{5,6}$

The Asian Pacific Society for Digestive Endoscopy has released a recommendation for digestive endoscopy practice in the era of the COVID-19 pandemic. The Indonesian Society for Digestive Endoscopy (ISDE) also announced standards for performing GI endoscopy during the pandemic. The ISDE recommendation comprises patient selection, endoscopy room, medical staff protection, recovery room, and equipment disinfection. The recommendations describe several points for performing GI endoscopy specifically on COVID-19 patients. The utmost importance of these ISDE recommendations is defining whether the patient has an indication for urgent, semi-urgent, or elective GI endoscopy. ${ }^{8}$

Only 7.5\% of Indonesian GI endoscopists performed endoscopic procedures on suspected or confirmed COVID-19 cases. ${ }^{3}$ Meanwhile, in South Korea, no data were available on

Received: February 19, 2021 Revised: April 26, 2021

Accepted: May 26, 2021

Correspondence: Rabbinu Rangga Pribadi

Department of Internal Medicine, Cipto Mangunkusumo National Central General Hospital, Jl. Pangeran Diponegoro No.71, Central Jakarta, Special Capital Region of Jakarta 10430, Indonesia

Tel: +62-21-3153957, Fax: +62-21-3148991, E-mail: rabbinurangga@gmail.com

ORCID: https://orcid.org/0000-0001-8450-4887

(c) This is an Open Access article distributed under the terms of the Creative Commons Attribution Non-Commercial License (http://creativecommons.org/licenses/by$\mathrm{nc} / 3.0$ ) which permits unrestricted non-commercial use, distribution, and reproduction in any medium, provided the original work is properly cited. 
endoscopists performing GI endoscopy in patients with suspected or confirmed COVID-19; however, according to a report by Han et al., ${ }^{4}$ no confirmed COVID-19 patients underwent the procedures as of March 21, 2020. Our GI endoscopy team adopted the highest ISDE standards when performing GI endoscopy for COVID-19 patients in real clinical practice. Along with the surge in COVID-19 patients at our hospital, GI endoscopy consultations in these patients also increased. We thus selected endoscopy indications and contraindications strictly. Our hospital provided a negative pressure operating room (OR), level 3 personal protective equipment (PPE) for the endoscopy team, and a dedicated endoscopy machine in the COVID-19 ward. The endoscopy equipment was also disinfected according to standard procedures.

Herein, we report serial cases of COVID-19 patients who underwent GI endoscopy at our hospital. The first patient was a 50-year-old woman with a chief complaint of hematemesis a day before admission. She had a history of liver cirrhosis of Child-Turcotte-Pugh class B. Other complaints were fever, shortness of breath, and cough, and she was diagnosed with suspected COVID-19. We performed esophagogastroduodenoscopy (EGD), visualized the esophageal varices, and performed esophageal variceal ligation. Hemostasis was achieved, but one day after the procedure, she experienced an episode of re-bleeding, which required subsequent esophageal variceal ligation. Unfortunately, she suffered from acute respiratory distress syndrome due to confirmed COVID-19 pneumonia in the intensive care unit and did not survive. The second patient was a 69-year-old woman with a chief complaint of an infected wound on her right leg. She had a history of uncontrolled type 2 diabetes mellitus. She underwent below-knee amputation and was admitted to the COVID-19 ward. Heparin was administered, but three days after initiation, massive hematochezia occurred. We performed urgent colonoscopy, which revealed a non-bleeding visible vessel in rectal ulcers. Diluted epinephrine injection and clipping were performed, and no re-bleeding episodes occurred afterward. The third patient was a 40-year-old man with a chief complaint of impacted garlic in the esophagus for nine hours before admission. He believed that swallowing garlic in one piece could cure COVID-19. EGD was performed to extract the impacted garlic. It was visualized in the esophagus, $17 \mathrm{~cm}$ from the incisors. As we were struggling to extract or push the garlic downward, we decided to perform argon plasma coagulation to cut the garlic into smaller pieces, which were then pushed into the stomach. The fourth patient was a 75-year-old man who presented with a history of hematemesis one day before admission. He was diagnosed with liver cirrhosis of Child-Turcotte-Pugh class B

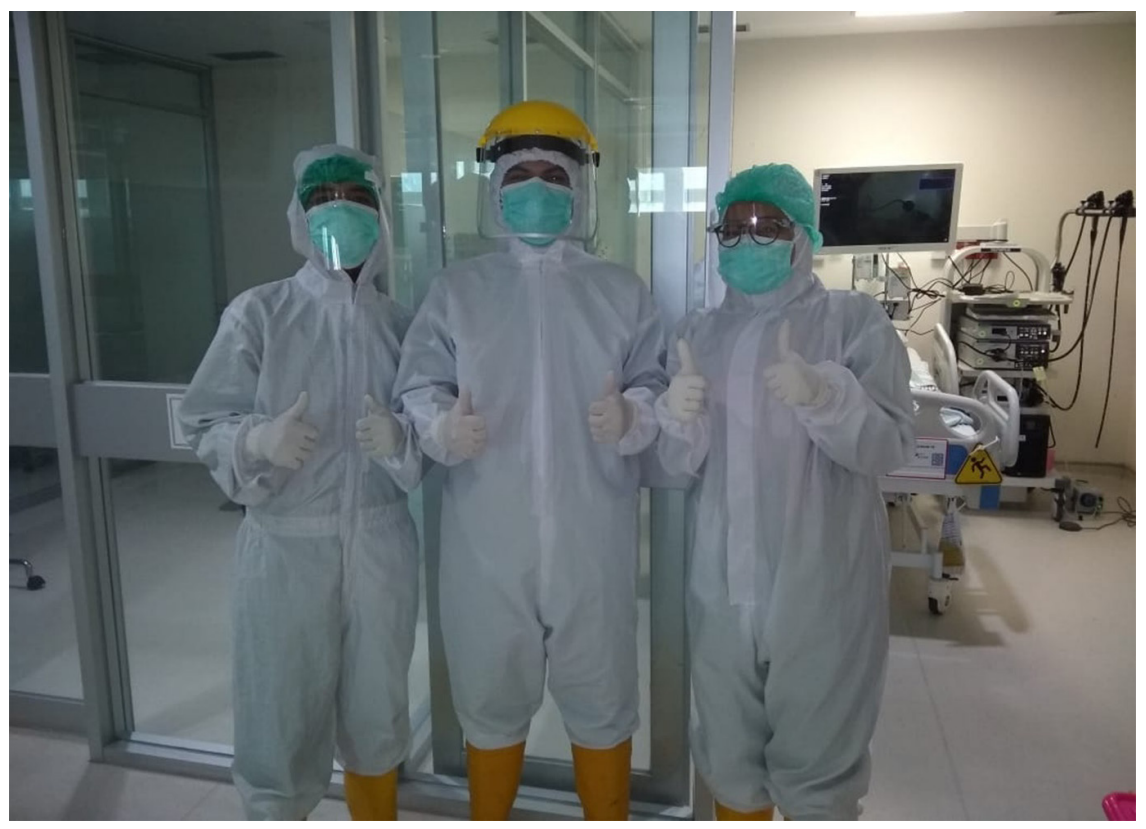

Fig. 1. The gastrointestinal endoscopy team wore level 3 personal protective equipment in the negative pressure intensive care unit. 
and type-1 isolated gastric varices. He had received a cyanoacrylate injection 6 months prior. EGD showed type-1 isolated gastric varices. He also received cyanoacrylate and lipiodol injections. The last three patients were discharged and sent home uneventfully.

All the aforementioned patients had things in common. They were diagnosed with confirmed COVID-19 and presented with GI problems, which necessitated urgent GI endoscopy. We implemented the highest ISDE standards to perform such procedures. We selected only those patients who had strict indications for urgent endoscopy such as upper GI bleeding, lower GI bleeding, and foreign body impaction in the esophagus without any contraindications. In South Korea, the indications for GI endoscopy were also restricted to urgent conditions such as GI bleeding, acute cholangitis, foreign body impaction, and luminal obstruction. ${ }^{4}$ Although the procedures were not specifically stated for COVID-19 patients, Zein et al. ${ }^{3}$ revealed that the three major indications of GI endoscopy during the pandemic were hematemesis and/or melena (73.5\%), GI symptoms with alarm signs $(60.5 \%)$, and hematochezia (57.5\%).

We arranged all the procedures in the negative pressure OR and intensive care unit to reduce the probability of SARS$\mathrm{CoV}-2$ transmission during the procedure. ${ }^{8}$ Han et al. stated that as a negative pressure endoscopy room was not available at their hospital, one endoscopy room with an open window was used for endoscopic procedures. Previous data have shown that upper GI endoscopy is an aerosol-generating procedure that can increase the risk of SARS-CoV-2 transmission. The virus has also been demonstrated in feces and is potentially infectious during colonoscopy. ${ }^{7}$ Therefore, one dedicated endoscopy machine for GI endoscopy (also used for bronchoscopy) was placed in the COVID-19 ward; it can be used in OR or intensive care unit.

Our GI endoscopy team, including doctors and nurses, were provided with level 3 PPE (Fig. 1) to ensure their safety during the procedure. The PPE consisted of a coverall suit, hair cap, face shield, N95 facemask, surgical mask, two pairs of gloves, and a pair of boots. The PPE in South Korea was not very different, as all endoscopy personnel were required to wear hair cap, goggles, N95 facemask, disposable gowns, two pairs of gloves, and a pair of shoe covers. ${ }^{4}$ All of the scopes and accessories were disinfected according to the standard protocol.

In summary, GI endoscopy can be performed on COVID-19 patients by implementing the highest standards of endoscopy according to the ISDE guidelines. For safety measures, the endoscopy team should select patients based on strict indications and contraindications, arrange the procedures in a negative pressure room, provide level $3 \mathrm{PPE}$, and disinfect the scope using a standardized protocol to decrease the risk of SARS$\mathrm{CoV}-2$ infection.

Conflicts of Interest

The authors have no potential conflicts of interest.

Funding

None.

Acknowledgments

The authors would like to express gratitude to the nurses of the gastrointestinal endoscopy team for their cooperation: Antan Taufik, Alain Pradana, Nenih, Zuryanah, Risa Ismadewi, Tri Ruhmatin Fitriyani, Darmayanti, and Tatik Irianingsih.

\section{Author Contributions}

Conceptualization: Rabbinu Rangga Pribadi

Data Curation: RRP, Amanda Pitarini Utari, Virly Nanda Muzellina, Saskia Aziza Nursyirwan

Formal Analysis: RRP, APU, VNM, SAN

Investigation: RRP, APU, VNM, SAN

Methodology: RRP

Project administration: RRP

Resources: RRP, APU, VNM, SAN

Supervision: RRP, Hasan Maulahela, Kaka Renaldi, Ari Fahrial Syam

Validation: RRP, HM, KR, AFS

Visualization: RRP

Writing original draft: RRP

Review and editing: APU, VNM, SAN, HM, KR, AFS

\section{ORCID}

Rabbinu Rangga Pribadi Amanda Pitarini Utari

Virly Nanda Muzellina

Saskia Aziza Nursyirwan

Hasan Maulahela

Kaka Renaldi

Ari Fahrial Syam https://orcid.org/0000-0001-8450-4887 https://orcid.org/0000-0002-7775-894X https://orcid.org/0000-0003-4949-7145 https://orcid.org/0000-0003-0166-7651 https://orcid.org/0000-0002-0396-4433 https://orcid.org/0000-0002-1092-9644 https://orcid.org/0000-0003-0041-3553

\section{REFERENCES}

1. WHO. Coronavirus (COVID-19) Dashboard [Internet]. Geneva: WHO; c2021 [cited 2021 Jun 10]. Available from: https://covid19.who.int.

2. COVID-19 S. Beranda | Satgas Penanganan COVID-19 [Internet]. [cited 2021 Jun 10]. Available from: https://covid19.go.id/.

3. Zein AFMZ, Pribadi RR, Khasanah U, Bestari MB, Syam AF. Clinical gastroenterology and gastrointestinal endoscopy practices during the coronavirus disease 2019 pandemic in Indonesia: an online nationwide survey. Clin Endosc 2021;54:348-355.

4. Han J, Kim EY. Sharing our experience of operating an endoscopy unit in the midst of a COVID-19 outbreak. Clin Endosc 2020;53:243-245.

5. Soetikno R, Teoh AYB, Kaltenbach T, et al. Considerations in performing endoscopy during the COVID-19 pandemic. Gastrointest Endosc 2020;92:176-183.

6. Maulahela H, Syam AF, Renaldi K, et al. A clinical and procedural guideline for gastrointestinal endoscopy units during COVID-19 pandemic era. Acta Med Indones 2020;52:431-435. 
7. Chiu PWY, Ng SC, Inoue H, et al. Practice of endoscopy during COVID-19 pandemic: position statements of the Asian Pacific Society for Digestive Endoscopy (APSDE-COVID statements). Gut 2020;69:991-996.

8. Indonesian Society for Digestive Endoscopy. Pedoman Klinis dan
Prosedural untuk Unit Endoskopi Saluran Cerna pada Masa Pandemi COVID-19 [Internet]. Jakarta: ISDE; c2021 [cited 2021 Jun 10]. Available from: https://pbpegi.com/language/id/pedoman-klinis-dan-prosedural-untuk-unit-endoskopi-saluran-cerna-pada-masa-pandemi-covid-19/. 